\title{
Size-shape relationships in the Mesozoic planispiral ammonites
}

\author{
Horacio Parent, Andrés F. Greco, and Matías Bejas \\ Acta Palaeontologica Polonica 55 (1), 2010: 85-98 doi: http://dx.doi.org/10.4202/app.2009.0066
}

Ammonites are of outstanding importance in dating events of the Mesozoic and in the study of mechanisms, modes and timing of evolutionary processes. These applications rely on a detailed understanding of their morphology and the modes of variation. It has been known for a long time that their shape is composed of a number of highly correlated features. A new model, called the ADA-model, is introduced for the study of shell morphology (size and shape). The new model is based on classic dimensions which are stable parameters throughout ontogeny, giving very close agreement between predictions and actual observations. It was applied in the exploration of the morphospace occupied by the planispirally coiled and the regularly uncoiled Mesozoic Ammonoidea, based on two new reduced morphospaces introduced for the analysis. Results obtained expose close relationships between size and shape, and general patterns in the ammonite shell morphology and morphogenesis. (i) The relative apertural height of the whorl section relative to the diameter of the shell $\left(\mathrm{H}_{2} / \mathrm{D}\right)$ is involved in definition of size and shape. (ii) This same dimension shows a strong tendency to $\mathrm{beH}_{2} / \mathrm{D}=0.3$. (iii) There are some geometrically possible shell shapes (or morphotypes) which seem to have not been developed since they are not known in the current record. Assuming the known ranges of protoconch size and whorl number as constraints, the ADA-model strongly suggests that these morphotypes have not been developed for the too large or too small sizes the shells would have attained, well outside of the actual size range of the planispirally coiled Ammonoidea. (iv) The law of covariation is shown to be a general pattern within the planispiral ammonites which describes structured variation of the shell shape. (v) A large fraction of the non-structured variation seems originate in the lack of correlation between the relative umbilical diameter and width of the whorl section.

Key words: Ammonoidea, size, shell shape, dimensionless analysis, reduced morphospaces, new model, Mesozoic.

Horacio Parent [parent@fceia.unr.edu.ar], Lab. Paleontología, Universidad Nacional de Rosario, Pellegrini 250, 2000 Rosario, Argentina; Andrés F. Greco [agreco@fceia.unr.edu.ar] and Matías Bejas [bejas@ifir-conicet.gov.ar], Departamento de Física and Instituto de Física de Rosario, CONICET, Universidad Nacional de Rosario, Pellegrini 250, 2000 Rosario, Argentina. 
This is an open-access article distributed under the terms of the Creative Commons

Attribution License (for details please see creativecommons.org), which permits unrestricted use, distribution, and reproduction in any medium, provided the original author and source are credited.

Forif Full text $(2,361.5 \mathrm{kB})$ 